\title{
Should Robots Blush?
}

Soomi Park

s.park@qmul.ac.uk

Queen Mary University of London

London, United Kingdom
Patrick G.T. Healey

p.healey@qmul.ac.uk

Queen Mary University of London

London, United Kingdom
Antonios Kaniadakis

antonios.kaniadakis@brunel.ac.uk

Brunel University of London

Uxbridge, Middlesex, United Kingdom

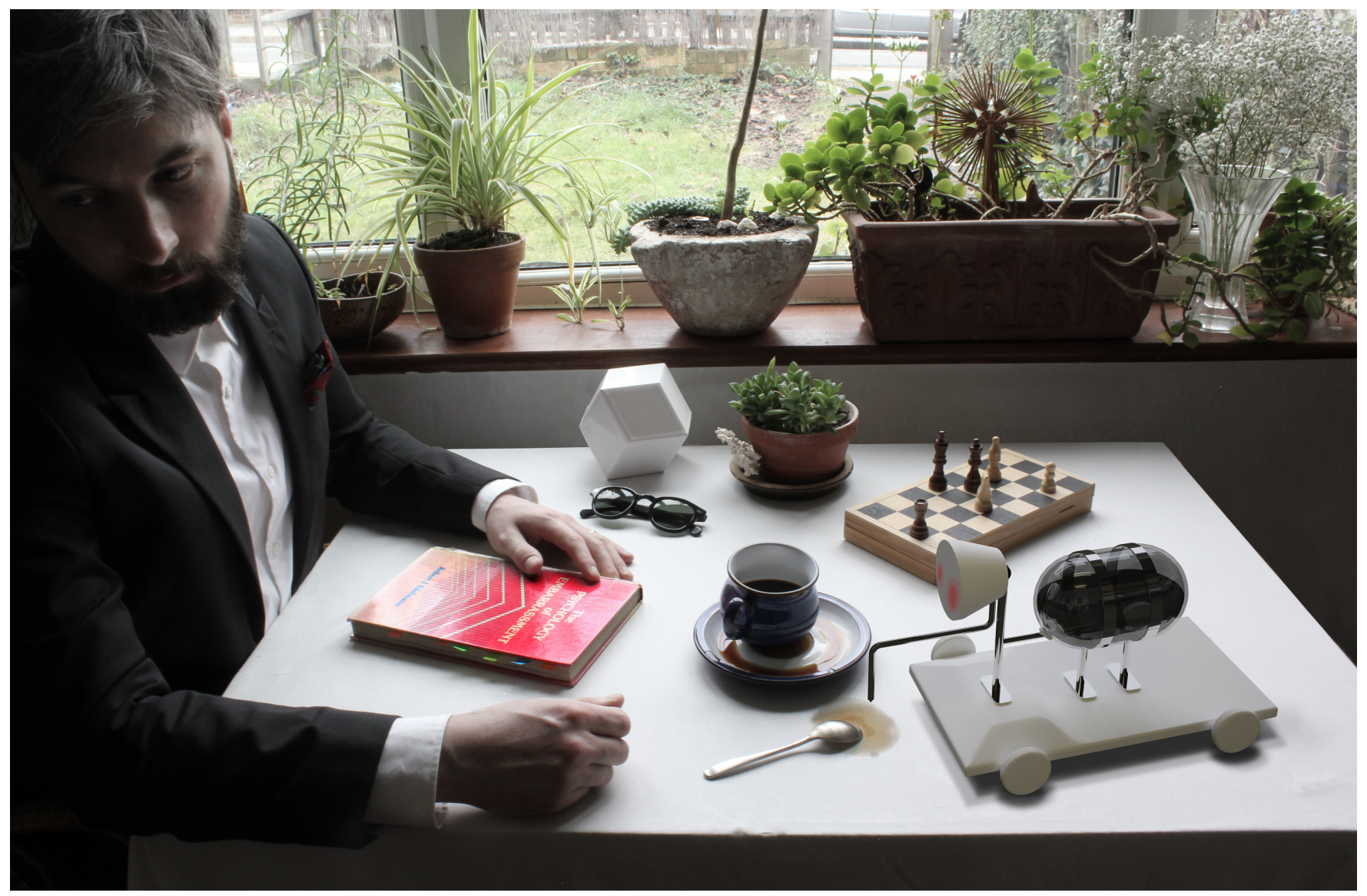

Figure 1: A visualization of one of the ideas of Embarrassed Robots. 2017

\section{ABSTRACT}

Social interaction is the most complex challenge in daily life. Inevitably, social robots will encounter interactions that are outside their competence. This raises a basic design question: how can robots fail gracefully in social interaction? The characteristic human response to social failure is embarrassment. Usefully, embarrassment signals both recognition of a problem and typically enlists

Permission to make digital or hard copies of all or part of this work for personal or classroom use is granted without fee provided that copies are not made or distributed for profit or commercial advantage and that copies bear this notice and the full citation on the first page. Copyrights for components of this work owned by others than the author(s) must be honored. Abstracting with credit is permitted. To copy otherwise, or republish, to post on servers or to redistribute to lists, requires prior specific permission and/or a fee. Request permissions from permissions@acm.org.

CHI '21, May 8-13, 2021, Yokohama, Japan

(c) 2021 Copyright held by the owner/author(s). Publication rights licensed to ACM. ACM ISBN 978-1-4503-8096-6/21/05 ..\$15.00

https://doi.org/10.1145/3411764.3445561 sympathy and assistance to resolve it. This could enhance robot acceptability and provides an opportunity for interactive learning. Using a speculative design approach we explore how, when and why robots might communicate embarrassment. A series of specially developed cultural probes, scenario development and low-fidelity prototyping exercises suggest that: embarrassment is relevant for managing a diverse range of social scenarios, impacts on both humanoid and non-humanoid robot design, and highlights the critical importance of understanding interactional context. We conclude that embarrassment is fundamental to competent social functioning and provides a potentially fertile area for interaction design.

\section{CCS CONCEPTS}

- Applied computing $\rightarrow$ Psychology; Sociology; • Humancentered computing $\rightarrow$ User studies; • Computer systems organization $\rightarrow$ Robotics. 


\section{KEYWORDS}

Human-Robot Interactions, Affective Robotics, Symbolic Interactionism, Embarrassment, Speculative Design, Cultural Probes, Design Workshop

\section{ACM Reference Format:}

Soomi Park, Patrick G.T. Healey, and Antonios Kaniadakis. 2021. Should Robots Blush?. In CHI Conference on Human Factors in Computing Systems (CHI '21), May 8-13, 2021, Yokohama, Japan. ACM, New York, NY, USA, 14 pages. https://doi.org/10.1145/3411764.3445561

\section{INTRODUCTION}

Robots are expected to play an increasingly important role in everyday life [71]. Many fundamental challenges still need to be addressed in order to achieve this ambition [93]. One of the most demanding of these challenges is social interaction. People spend approximately a third of their waking hours engaged in conversation [63] and it is the primary environment in which assistive, companion and collaborative robots will operate.

The basic challenges natural interaction poses for robots are well understood $[50,62,79]$. It requires coordinated use of complex multiperson and multi-modal signals with millisecond and millimeter accuracy including: posture, gesture, orientation, head movements, facial expressions, gaze, utterances, vocalizations, touch and even blinks [45]. The meaning of these signals also varies with context. People are sensitive to the specific sequential context of each unfolding interaction, the evolving beliefs and intentions of participants, and to the wider social, moral and ethical norms of the community in which an interaction occurs.

Inevitably, social robots will sometimes fail to meet these challenges. This raises a fundamental design question: how should robots deal with failure? When people encounter problems in an interaction one common response is embarrassment. Embarrassment involves both the individual recognition of a failure and the mutual, social acknowledgment of that failure [33]. Importantly, embarrassment also commonly elicits sympathy and assistance. Conversational partners typically smile or laugh in response to displays of embarrassment and often offer help [53]. This makes embarrassment potentially valuable as a means of improving the acceptance of social robots in everyday life and for facilitating interactive learning to improve robot performance.

Human responses to robot errors, including embarrassment, has received significant attention in the literature [5, 12, 19, 40, 44, 67]. However robot detection or production of embarrassment has only rarely been discussed $[1,27]$. How, when and why should robots produce signals of embarrassment in everyday human-robot interaction? Speculative design, introduced by Dunne and Raby [22], provides a valuable, prospective way to explore the possible design responses to these questions.

Speculative design uses design methodologies to construct design fictions. Using this approach, Dunne and Raby illustrated alternative emotional interactions with robots through their project, Technological Dreams series No 1: Robots [21] (see Figure 2). This project shows how our concepts of human-robot interactions(HRI) can be expanded by, for example, creating representations of potential human-like interactions with robots that express emotions such as neediness or hysteria. This project prompts critical reflection on what new types of interdependence and relationships could be created if robots were "subservient, intimate, dependent or equal" to humans [21]. The project explores which simple human interactions and behaviors (e.g., attention seeking, avoidance, or anxiety) would be likely to inspire empathy. The project also shows ways in which a robot could deliver human 'likeness' without requiring high levels of morphological or emotional similarity to humans.

This paper presents a speculative design approach to the use of Goffman [34]'s ideas about the importance of embarrassment in human interaction and their potential application in HRI. Goffman proposes that social interactions are primarily concerned with impression management and embarrassment arises when this fails [34]. Individuals can experience this emotion in any interactions involving others. The signals of embarrassment are thought to be universal although the situations in which it is appropriate vary according to cultural norms $[33,53]$. Our working assumption is that robots, like people, will never perform perfectly and robotics therefore needs to learn from the ways people cope with their mistakes in social interaction using embarrassment displays i.e., specific signals of physiological and behavioral changes such as blushing $[25,26,33]$.

We develop a speculative design concept 'Embarrassed Robots' to investigate how Goffman's ideas could be applied in social robotics. What role could embarrassment play in real-life social interactions? What forms of robot expression would convey embarrassment? Furthermore, should robot embarrassment displays be a key part of robot impression management? The investigation is developed in two parts:

(1) A series of cultural probes entitled "Your Embarrassed Robots" to explore people's perceptions of embarrassment, especially the situational causes of the emotion.

(2) A speculative design workshop, "Do Robots Blush?" to explore what benefits robots would have by signaling embarrassment.

The goal of these investigations is to probe the ways in which robots can be designed to produce and respond to signals of embarrassment. The contributions we aim to provide to the HCI community through this paper are:

- To provide an alternative perspective on the kinds of 'humanlikeness' that are appropriate when designing non-human object's capabilities for social interaction.

- To highlight the potential relevance of symbolic interactionism for social robot design and, within this, the way embarrassment functions in our everyday social interactions.

- To develop methods and processes that provide a new framework for designing affective social robots.

- To produce design provocations that explore the potential uses of embarrassment in HRI.

\section{BACKGROUND}

Two factors inform our approach: 1) the role of embarrassment in social interaction and 2) the use of speculative design to develop social robots. Before considering each of these in more detail it is useful to summarize the wider context of work on HRI.

One intuitive approach to design for HRI is to develop physically anthropomorphic robots (i.e., Humanoid or Android). These robots 
have human-like morphology (e.g., head or limbs) [41, 42, 49, 77] and often some verbal language ability [90]. This gives the systems an intuitively recognizable interface. The effectiveness of humanoid robots for interaction has been investigated in a variety of settings, such as children's education [47, 86], autism therapy [7, 17, 76, 94], elderly care $[15,74]$ and driving support [70]. An important problem for these systems is that while their appearance suggests a potentially high level of social or interactional competence the underlying systems often cannot sustain the expectations this generates. One result of this issue is the feeling of creepiness referred to as the uncanny valley where low fidelity humanoid robots are perceived as more acceptable than higher fidelity humanoid robots $[16,29,55,61,69]$.

Another important approach to HRI has been to focus on affective displays, typically nonverbal facial expressions such as happiness, fear, anger and surprise but also implemented in nonhumanoid robots. For example, Breazeal [9] designed the elf-like Kismet robot with a capacity to communicate its motivational system through affective displays and non-verbal vocalizations. The robot could display different behaviors by learning and recognizing people's emotional expressions. A more recent example that runs counter to this trend is Pepper, an intelligent affective robot from Softbank Robotics [85]. Pepper uses a number of different sensors (e.g., infrared, sonar, laser, bumper, etc.) and a machine vision system to detects facial expressions and the surrounding environment and then communicates through speech and body movements but does not use facial expressions.

Design for HRI often focuses on enhancing robot social environment recognition (e.g., human social behavior, interaction, user's emotion, etc.) [56]. One reason for this is the relatively restricted use scenarios, in which the robot has often been utilized as either a "persuasive machine" (e.g., in autism therapy) or "avatar" (e.g., in remote communication) [30]. Although more recent interest for developing HRI expands the target social scenarios to daily routine support (e.g., home assistant robot concepts, Bot Care and Bot Air [78]), the primary role of these robots is service provision (e.g., health care, air purification, etc.).

\subsection{Embarrassment in Social Interactions}

Embarrassment occurs when people unintentionally violate social norms (or rules) in everyday human life [24, 33, 52, 66, 87]. A key feature of embarrassment, and one that distinguishes it from other social emotions such as shame, is that it is the co-presence of others and their (assumed or actual) appraisal of a situation that is the main trigger for experiencing and displaying embarrassment [23, $34,36,68,82]$. This locates embarrassment in the social system rather than in the individual [p.108 36]. It also gives embarrassment a foundational importance in social interactions beyond that given to specific expressions of emotion such as smiles and frowns. The threat of embarrassment is constant and people's desire to avoid it are thought to be universally relevant for all social interactions in all cultures although the specific situations in which embarrassment occurs vary [33].

Goffman, who draws on Cooley's concept of the looking-glass self [14], conceives of individuals as having two selves in everyday life: the virtual self which is a specific identity formed by idealized expectations of how people want to appear to others and the real self that is formed from the individual's actual behaviors and other people's responses to them [34]. The real self poses a threat to the virtual self in all social interactions and consequently there is a constant risk of embarrassment [33]. To cope with this people engage in active "impression management" in order to minimize or reduce embarrassing experiences.

This concept of embarrassment is constitutively social. Scheff [81] characterized the role of embarrassment in Goffman's view as a defensive "an interactional device" used when individuals behave against their idealized expectations in everyday life. The interactive disruption of idealized social roles is the critical reason for experiencing embarrassment $[39,91]$ and it provides ways for individuals to demonstrate their overall "[...]commitment to social organization, values and convention" [p.137 46]. It is also through the experience of embarrassment that people can develop their understanding of social rules, such as self control, modesty, manners and privacy [p.239 92].

Embarrassment is manifested in specific interactional moments and associated with particular verbal and non-verbal cues [53]. The characteristic outward signs of embarrassment includes behavioral displays such as aversion of eye contact, shifting gaze, looking down, touching face, smile control, nervous smiling or laughter [e.g., 2, 25, 26, 33, 43, 51]. These responses are associated with physiological changes such as blushing or temperature change [e.g., $83,84]$. Observers can reliably recognize these displays of embarrassment and discriminate them from displays of related emotional expressions (e.g., shame, amusement, guilt) [51, 53]. Displays of embarrassment can help the embarrassed individual's impression positively [33]. It not only shows the individual's recognition that they presented an undesirable self but also manifests that individual's desire remedy the situation [p.270 33].

Embarrassment is also social in the sense that other participants also often reciprocate expressions of embarrassment in response to an actor's embarrassment [33]. Embarrassed speakers often apologize, use humor, provide an account for their transgression and so do their listeners [64]. Miller [65] demonstrated how observers who witness an individual's embarrassment respond both cognitively and physiologically.

The potential importance of embarrassment for HCI (sometimes referred to awkwardness or shyness) has been noted for users or audiences interacting with technologies including robots. However, the emotion is often treated as "a secondary concern and surprising finding" rather than an opportunity for design [19]. Most studies see embarrassment as a problem that is diagnostic of uncertainty or anxiety about an interaction [6, 13, 40,48]. For example, Choi et al. [12] showed that people experience embarrassment more frequently while interacting with the "tele-operated robots", which were controlled by a human operator rather than autonomous robots. Furthermore, the majority of these studies focus their perspective on human embarrassment rather than the technology's embarrassment.

Embarrassment can also be a resources for enhancing engagement with technological systems. Some studies have identified embarrassment as a facilitating medium for engaging experience among the players of games [18, 48], and between users and technologies [48]. Choi et al. [12] noted that even though 
their participants were more embarrassed interacting with teleoperated robots they also perceived them as more sociable than autonomous robots. Pan and Hamilton [73]also found people perceive virtual characters more positively when they showed behavioral displays of embarrassment. This highlights how embarrassment could be an indicator not of problems but of interactional sophistication.

\subsection{What Could Robots Do in Our Social Interactions?: Speculative Design and Social Robots}

The work presented here crosses the boundaries between speculative design, cognitive psychology and social robotics. Speculative design is a practice, and language that is employed to speculate on and illustrate alternative future scenarios. This design methodology was introduced by Dunne and Raby [22] and has often been referred to as 'design fiction' [8] within the HCI community.

Speculative design is a useful methodology for illustrating creative future scenarios, because it mainly deals with 'unreality'. Since the design method allows for the removal of prejudgment, which is generally based on our experience in real life, it opens up the opportunity to view the ideas presented from a creative perspective [22]. By rejecting the 'market-forces' that influence conventional design, whilst still working within reality's boundary, speculative design offers an alternative but important perspective on the future. Dunne and Raby argue that design plays a critical role in expanding people's perspective on possible futures [22], we adopt this methodology for speculative design of Embarrassed Robots.

Research in HCI has seen growing interest in speculative design. Lindley and Coulton [57] see it as "[...] something that creates a story world [...] prototypes something within that story world". They note that considering what "something" would be is the critical point in their definition. Markussen and Knutz [60] suggests this design approach may be used for formulating initial concepts or ideas, which can lead to precise articulations through diverse media later.

A speculative designer and design researcher, Auger [3] argues that the method not only shows future scenarios with the possible implications of contemporary technology, but also offers a space to rethink technology itself (see also Lindley and Coulton [58]). Design fiction can be used to explore prototypes of technologies or devices that do not exist and develop plausible future scenarios. A strength of the method is that it provokes discussion on reshaping the possible developmental directions of existing technologies' technical and creative models outside of established narratives about the future.

Although the most obvious approach to human-likeness in interaction for robotics is to use humanoid morphologies or affective expressions, speculative design has explored alternatives based on more abstract concepts of social interaction and their potential application to social robot scenarios. Auger and Loizeau [4]'s Happylife project shows how intelligent technologies at home might create more bonding relationships among the family members (including the technological system itself) through recognizing, signaling and predicting emotional status (see Figure 2). Trujillo [88] addresses how environmental elements could be changed in order to accept the robots as our cohabitants through his project, With Robots (see
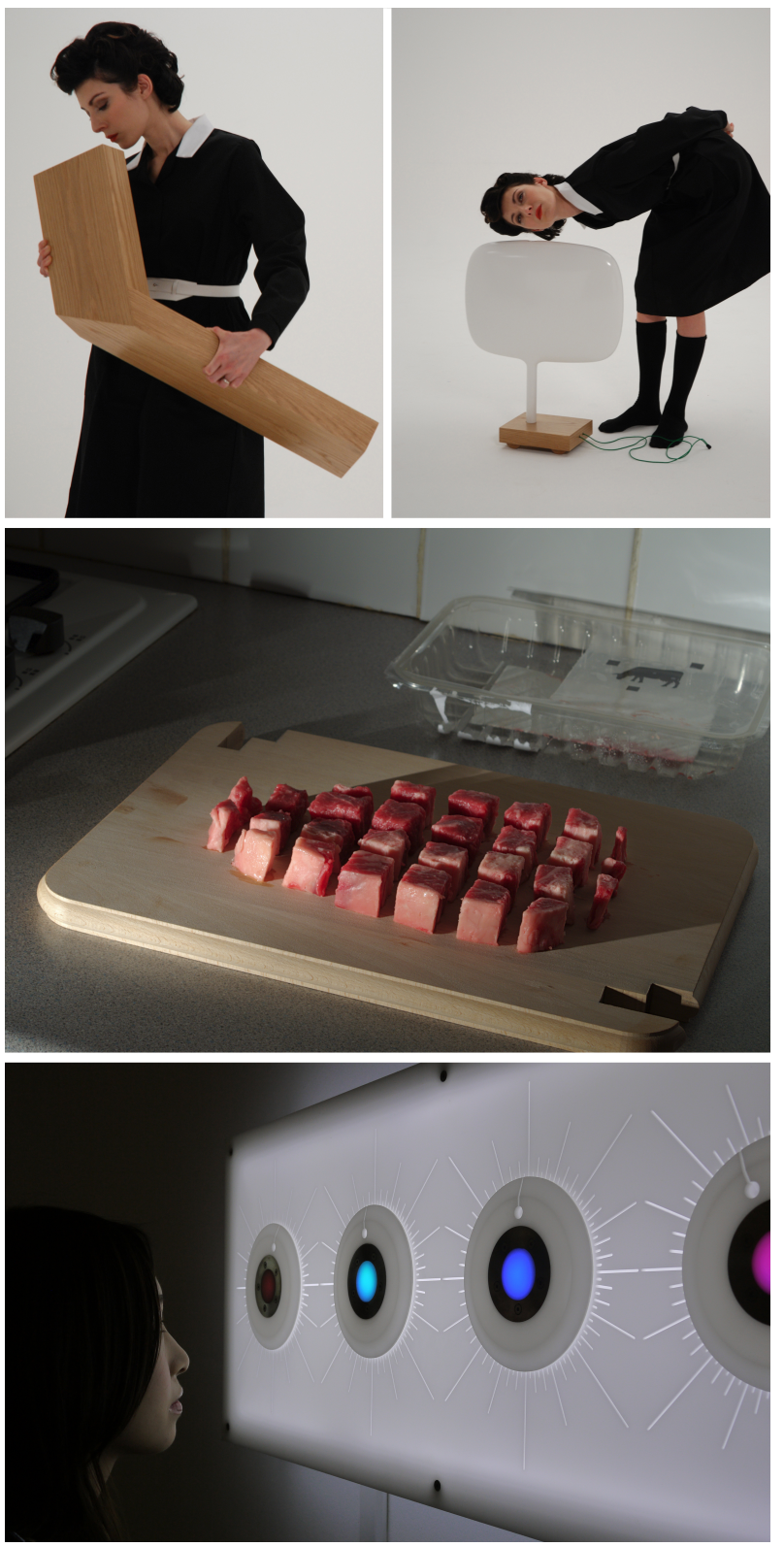

Figure 2: (top):Technological Dreams series No 1: Robots (top-left)Sentinel: The robot uses retinal scanning technology to authenticate the user via his or her iris scan. The robot requires enough time to complete the scan hence the user needs to hold the robot for a long time. (top-right) The Needy One: the robot is extremely smart but needy; hence it allows the user to maintain a feeling of control ( $\odot$ Dunne and Raby; Photograph by Per Tingleff). (middle): With Robots illustrates home environments that are altered to allow cohabitation with a robot (๑Diego Trujillo). (bottom): Happylife shows a family home containing an intelligent machine which recognizes each family member's emotional status (๑Auger and Loizeau). 


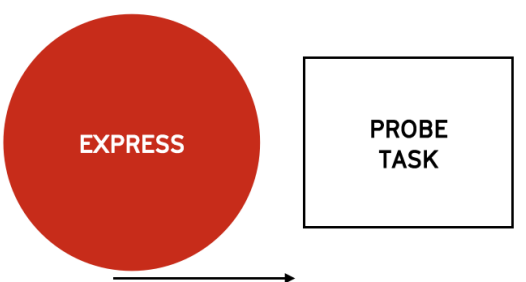

INVESTIGATOR

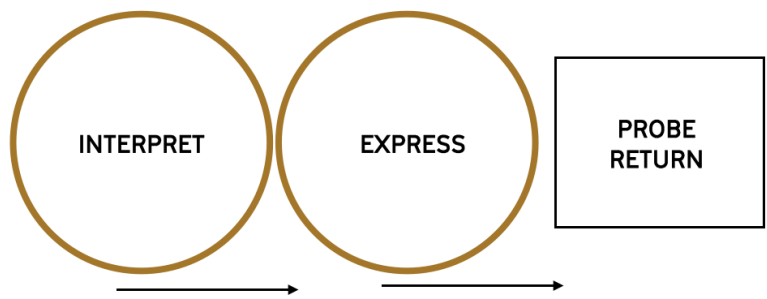

VOLUNTEER

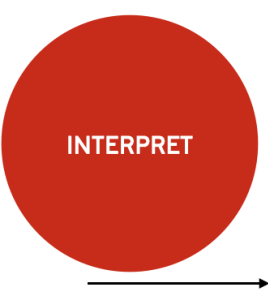

INVESTIGATOR

Figure 3: Schematic Diagram of the use of cultural probes process. Stage 1: Construct probe kit with a series of activities, questions and tools then distribute; Stage 2: Volunteers interpret the task and express their ideas ; Stage 3: Collect responses (returned probes); Stage 4: Interpret the returned probes as the outcomes (Redrawn and modified version from Gaver et al. [32]).

Figure 2). Instead of focusing on human-like robot mechanics and engineering, Trujillo suggests adapting the living environment to allow robots to easily co-habit with humans (e.g., modified mug handle, the edge of chopping board and plates, etc.). The project raises a critical question for current research in robotics: if we want robots to live with humans, what changes would be needed to follow to accommodate the robots? Usher [89] designed a robot called Pareidolic Robot, whose function is to capture interesting moments within nature (i.e., pareidolia from clouds) that we often miss seeing due to fast-paced life-style patterns. The concept allows people to reflect on their interactions with time and nature, which they may have lost track of. The project suggests an alternative role for robots, one that link us to our environment and the seasonality of nature, instead of only serving or laboring for humans.

\section{METHODS}

We follow two steps to develop design rationales for Embarrassed Robots: cultural probes and a speculative design workshop. These methods fall broadly within the "participatory design (PD)" approach. The general goal of using PD in design practice is to create possible user scenarios and prototype artifacts through a collaborative design process $[20,38]$. Since our aim is to engage people in speculative design, the unfamiliarity of the concept could be communicated more successfully through a provocative PD approach in which we involve people in building the design speculations. Our studies were reviewed and approved by Queen Mary Ethics of Research Committee (reference no: QMREC2016a, QMREC2017a).

Both studies inform ideas about the purpose, role, affective signal and form of the robot. The cultural probes provide the general background on the context and causes of everyday embarrassment. They also explore possible expressions of the emotion that could be applied to an intelligent machine. The speculative design workshop offers an in-depth discussion of the research questions and exploration (through prototyping more detailed designs and scenarios) of the roles embarrassed robots could play in everyday social interactions.
Both studies were conducted at the Design Museum in London as part of a residence program. This provides a natural, gallery context for speculative design [p.140 22] and access to a specific audience who are naturally interested in this approach.

\subsection{Your Embarrassed Robots: Cultural Probes}

Cultural Probes were introduced by Gaver et al. [31] as a design-led approach to understanding potential users and contexts through their engagement on a given task. The method asks participants to voluntarily share their interpretations on the questions provided through probe materials which are returned to the researcher. The cultural probes process is generally divided into 4 stages (see Figure 3). This research method has been used widely in design research and social science studies as a technique to generate qualitative data.

The aim of the cultural probes developed for this project was firstly to explore people's perception of sociable affective technology by looking at how they conceptualized and characterized their visualizations of the robots. Second, to understand where they placed robots within their interaction environment by analyzing the social or cultural background contexts.

We designed a series of paper nets (i.e., paper models for a cube, pyramid and hexagon) named "Your Embarrassed Robots" and gave them away to the museum visitors to freely design their embarrassed robots. We wrote three questions next to the title of the probes: What does it look like? What makes it embarrassed? How does it express embarrassment? The first question requests people to design an embarrassed robot using the paper nets provided. We encouraged the use of combinations of patterns and additional materials or drawings in the design of prototypes. In order to answer the second question, people need to think about possible causes of embarrassment. We suggested placing the robot in a social or cultural environment to provide concrete scenarios. Finally, with the third question people could explore their ideas on what kinds of signals could be used to convey robot embarrassment. To return 
their ideas, people were asked to take a photo of the robot prototype and send it via email or upload on their Instagram account with a mention of our project account. All instruction to participate as well as the email address and the project Instagram account were printed on the same page of the patterns. The nets were also available to download from our project website. We also held two making workshop sessions, where people could use a drop-in desk space to build the paper prototypes. One of the sessions was held at an art gallery in London as a part of a multidisciplinary symposium, instead of the museum, to collect the ideas from the people who are interested in multidisciplinary research fields.

\subsection{Do Robots Blush? Speculative Design Workshop}

To investigate an in-depth understanding of the people's notion of embarrassment and social robots, we used a speculative design workshop. The workshop method encourages a small group of people to learn and share new knowledge and to contribute their ideas on a domain-specific issue. It aims primarily at exploration not generalization and is used here as a way to help develop research questions and shape possible design scenarios rather than generate specific answers [p.72 72]. The making element avoids any technical issues and constraints focusing instead on exploration of contexts and concepts of robot embarrassment and the social, ethical and political implications of intelligent technologies in our everyday life in the future. The outcomes provide clues for building a design rationale for Embarrassed Robots, which requires a critical understanding of what forms and signals could communicate a machine's embarrassment.

The PD workshop was held in a creative space at the Design Museum. We recruited eight participants ( 1 female; 7 males) using a pre-ticketing method through the museum's online promotion. The background of participants varied, which included: academics, research students and practitioners from design engineering, graphic design, product design, critical design, cognitive science, social science and data science.

The workshop was divided into two parts; 1) Lecture Session: a series of introductory talks from experts in cognitive psychology, robotics and design. 2) Design Session: hands-on designing and building one's own Embarrassed Robots (see Figure 4).

3.2.1 Pre-knowledge sharing. A week prior to the workshop a small preparatory task was sent via email in order to warm-up participants' interest and their understanding of the workshop topic as well as to help anchor their approach in their own personal context. The task required them to provide two images that represent their ideas on the following statements:

- something that they find embarrassing

- something that another person finds embarrassing

We informed the participants that the images they were to submit could be of an object, a situation or material; they could take place in either public or private spaces, indoors or outdoors, involving or excluding people. The participants were encouraged to submit these images via email by the day preceding the workshop. We printed the submitted images and displayed them in the workshop space. We displayed the images without any reference to the prompting

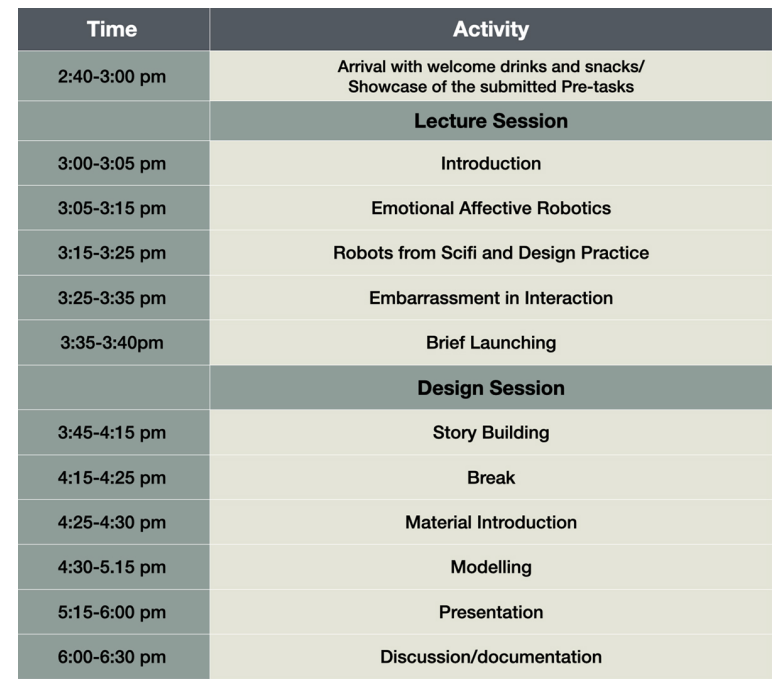

Figure 4: The workshop was divided into two sessions: Lecture Session and Design Session

statements. The participants had a moment to view the images at arrival.

3.2.2 Lecture Session. The Lecture Session was planned to help the participant's understanding of the topic by sharing technical and theoretical perspectives on embarrassment, robotics and design fiction. Two academics from cognitive science and robotics gave overview talks summarizing the social importance of embarrassment and the state-of-the-art in robotics. Two professional designers then presented explorations on the topic with examples from science fiction cinema and previous design projects. Through the experts' talks, we expected the participants to not only understand the role of embarrassment and social robots in our everyday life, but also to be able to formulate their design ideas for the next session.

3.2.3 Design Session. Participants were asked to construct potential scenarios for living with embarrassed robots, and prototype the robots by exploring material, form, and behavior. The participants were randomly assigned into pairs and asked to work collaboratively. To help the participants enter into the speculative design process, we suggested they imagine they are an ethnographer who has just discovered an 'Embarrassed Robot' in a specific place. The intention of this setup was to challenge the participants to both think about a subject that is fictional, whilst bringing a plausibility to their scenario by contextualizing the surrounded environment or situation.To structure the design process, the workshop was divided into two sections: 1) Story Building; 2) Modeling. Each section was split into subsections organized around reflective questions to guide participants through the process (See Figure 5). Through the Story Building session, we wanted to figure out what social interaction environments are commonly considered as the locations that generate embarrassment and the role of the robot. With the Modeling session, we wanted the participants to consider what forms would be appropriate for a social and emotional robot. By 


\begin{tabular}{|c|c|c|c|}
\hline \multicolumn{2}{|r|}{ Story Building } & \multicolumn{2}{|r|}{ Modeling } \\
\hline $\begin{array}{c}\text { Situations } \\
\text { (15mins) }\end{array}$ & $\begin{array}{l}\text {-Where does this robot exist? } \\
\text { - Bring the artifact from the location } \\
\text { you found the robot }\end{array}$ & $\begin{array}{c}\text { Physicality } \\
\text { (15 mins) }\end{array}$ & $\begin{array}{l}\text { - What does the embarrassed robot } \\
\text { look like? } \\
\text { - Does it stay in a single place or } \\
\text { move around? } \\
\text { Does it interact with people } \\
\text { or is it alone? } \\
\text { - How does it communicate? }\end{array}$ \\
\hline \multirow[t]{2}{*}{$\begin{array}{l}\text { Purpose } \\
\text { (15 mins) }\end{array}$} & \multirow[t]{2}{*}{$\begin{array}{l}\text { What are the robots doing there? } \\
\text { Does it have a purpose? } \\
\text { (e.g., entertainment, service or } \\
\text { nothing at all) } \\
\text { - Bring an item related to their job }\end{array}$} & $\begin{array}{c}\text { Realization } \\
\text { (10 mins) }\end{array}$ & $\begin{array}{l}\text { - How does the robot know that } \\
\text { it is doing well? } \\
\text {-What does correct or incorrect } \\
\text { mean to them? } \\
\text { Are they challenging to something? } \\
\text { - Do they have human-like actions? } \\
\text { Or do they realize in another way? }\end{array}$ \\
\hline & & $\begin{array}{l}\text { Manifestation } \\
\text { (20 mins) }\end{array}$ & $\begin{array}{l}\text { - Do they show physiological change } \\
\text { or behavioral change? } \\
\text { Do they change at all? }\end{array}$ \\
\hline
\end{tabular}

Figure 5: Structure of the Design Session

responding to tasks, our objective was to allow participants to question whether a robot's embarrassment displays need to follow the human's processes, or could be different.

At the beginning of Modeling section, the two designers from the Lecture session gave a short introduction to the workshop materials that participants could use for prototyping. Diverse prototyping materials were provided to encourage the participants to freely illustrate their ideas on the machine's form and emotional expression. The materials included general stationery (e.g., papers, pens, scissors, cutters, and glues); basic prototyping materials (e.g., tapes, fabrics, wires, play-dough, balloons); basic electronics (e.g., motors, LEDs and batteries); smart materials (e.g., thermochromic paint and ink); mechanical prototyping materials (e.g., laser cut acrylic wheels); materials from recycling (e.g., plastic cups, tights, wooden sticks). The designers provided support to participants during the design session together, especially for dealing with materials and their idea generation. The design session ended with a short presentation from each group (5 mins/group) including a demonstration of their prototype.

3.2.4 Round-table Discussion. After the presentation session, participants were encouraged to participate in a 30-minute round-table discussion. This was a critical part of the workshops, since participants could share their thoughts on the social, political and ethical concerns around current robotics, 'human-likeness' in 'nonhumanlike' objects, and the benefits of affective signals of robots, etc. We also used this discussion to gather the participants' feedback on their experience of the process. An email after the workshop provided a channel for any additional feedback which could not be mentioned during the discussion session due to the time limit. Four participants replied they had a generally positive experience, and two commented that reducing the facilitators' involvement during the round-table discussion would give the participants more chance to speak.

\section{OUTCOMES}

\subsection{Their Embarrassed Robots: The Returned Probes}

Twenty-two prototype images were returned. No time limit was applied for releasing and receiving back the cultural probes. Seven images were sent via emails; Thirteen prototype images were collected through the drop-in making sessions (three from the museum session, ten from the art gallery session); two were returned by Instagram. Three images were excluded from the analysis since the prototypes were made by participants under the age of 16 and outside the scope of our ethics committee approval. Respondents' backgrounds were generally not stated, since more than half of them were from the art gallery session who are working or researching in the fields of art, design and computer science. All returned cultural probes were also published on the project's Instagram account to share with the broader public.

The nineteen cultural probes returned were diverse but there were also some obvious similarities between design. For the making process, people tended to use just one pattern to build the robots: 10 robots were built through one net only; seven robots were constructed with two or more nets. A few prototypes were made with other materials. One cultural probe was a written statement, not a physical prototype. The majority of people drew on the pattern to illustrate their robots. Half of the submitted designs had additional materials such as sticks, balloons, colored papers or acrylic shapes.

Nine robots used some form of physical similarity to humans, such as a face, eyes, legs, arms, a mouth, internal organs and body structures. Only three robots took the shape of a specific nonhuman object: a ball, a flower and a fruit basket. Seven prototypes 


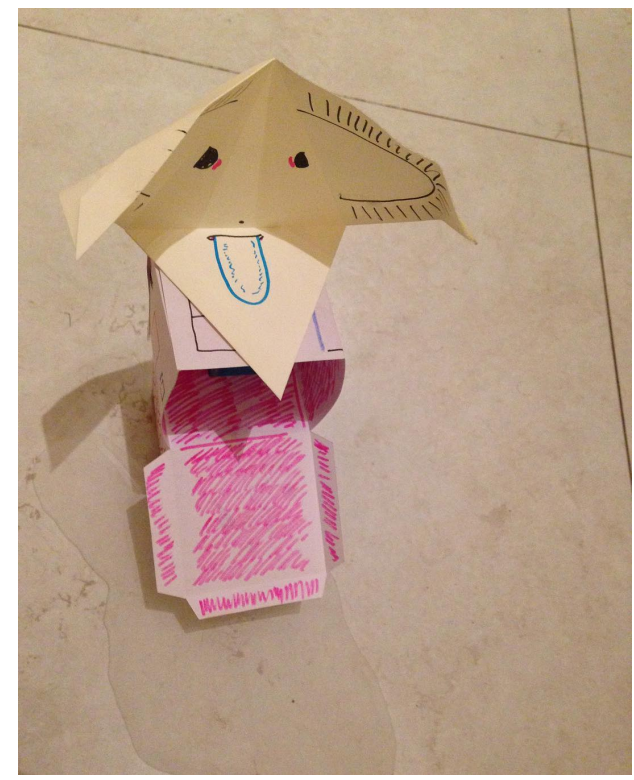

Figure 6: One of the cultural probes: This probe was returned with all tasks completed as well as the three questions. The design of robot consisted of three paper patterns (two cubes and one pyramid) which were stacked in a similar formation to a shape of human physique. The robot has human-like facial features (e.g., eyes, nose, mouth, tongue, ears). The robot displays embarrassment through the tongue out behavior as well as showing its internal structure. The robot is placed on the floor and surrounded by a body of water. The participant described that the robot is embarrassed because it wet itself.

have abstract forms, such as distorted shapes of the given patterns, combined with other materials, or simply the constructed net without any modification.

Human-like facial expressions seemed to be the dominant approach to signaling embarrassment. For example, Six people used eye expressions (tearful or sad eyes, smiley eyes, looking up eyes) Six used mouth shapes such as wiggly mouth, open mouth or tongue out expression. Facial blushing was also shown in one prototype. Four designs used color changes to signal emotion. One prototype used changes in the size and volume of the physical body as a signal, and two robots had no expression (i.e., no additional materials, drawings or figure changes).

Most participants provided some written explanation of the cause of embarrassment rather than putting their robot in a particular environment. In the drop-in workshops participants offered verbal or written descriptions and people who sent photos of the robot over email or Instagram also provided written descriptions.

Together with the descriptions and the illustrated situations of the probes, we can summarize the designs as falling into four general categories based on the rationale provided for the robot's embarrassment: 1) noticing stigma or difference (e.g., facial spot, wobbly legs, no lips, different language, being naked, exposure of body part); 2) failing to realize the desire (e.g., wrongly forming the specific shape, desire to be different object, exposure of personal behavior); 3) making small mistakes (e.g., spilling ketchup, being late, bringing a wrong item, got stuck in a space, wetting itself); 4) no external cause (e.g., innate shyness). There was one answer which rejected the basic premise of the exercise:

"How is a robot embarrassed if they have no emotions"

\subsection{Robots Do Blush! Design Outcomes from the Workshop}

For the pre-task, the images addressing the first statement, 'something that they find embarrassing', were delivering situations involving small accidents that could happen in everyday life. Six submitted images were: (a) an angry person during a protest; (b) being late; (c) mistakenly entering onto a bus lane while driving; (d) spilling red wine on a white shirt; (e) nose-picking; (f) falling down in a public space. The responses to the second statement, 'something that another person finds embarrassing', showed a broader meaning of being an observer of embarrassment. Seven images were about: (g) an English flag; (h) when a person cannot understand what the other person says; (i) being in a sauna; (j) falling down in public space; (k\&i) politicians and their unnatural activities; (m) wetting oneself.

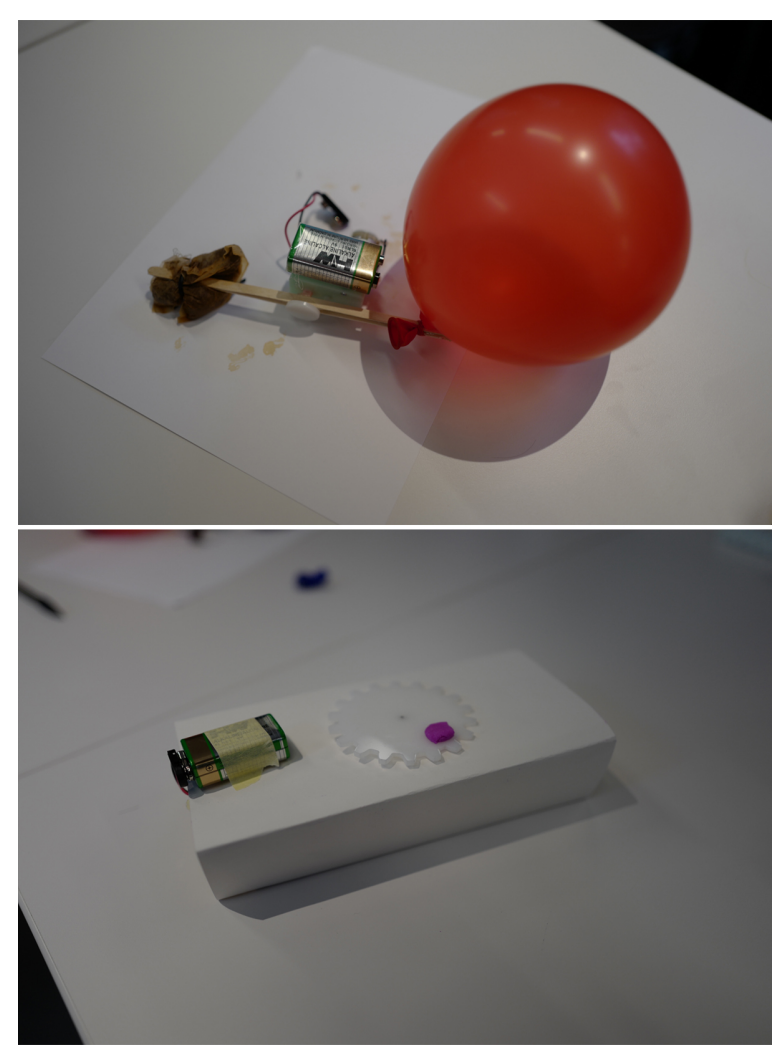

Figure 7: Two design outcomes of Group 1: (top) A robot moves constantly and leaves footprints (bottom) A robot makes non-stop vibrations 

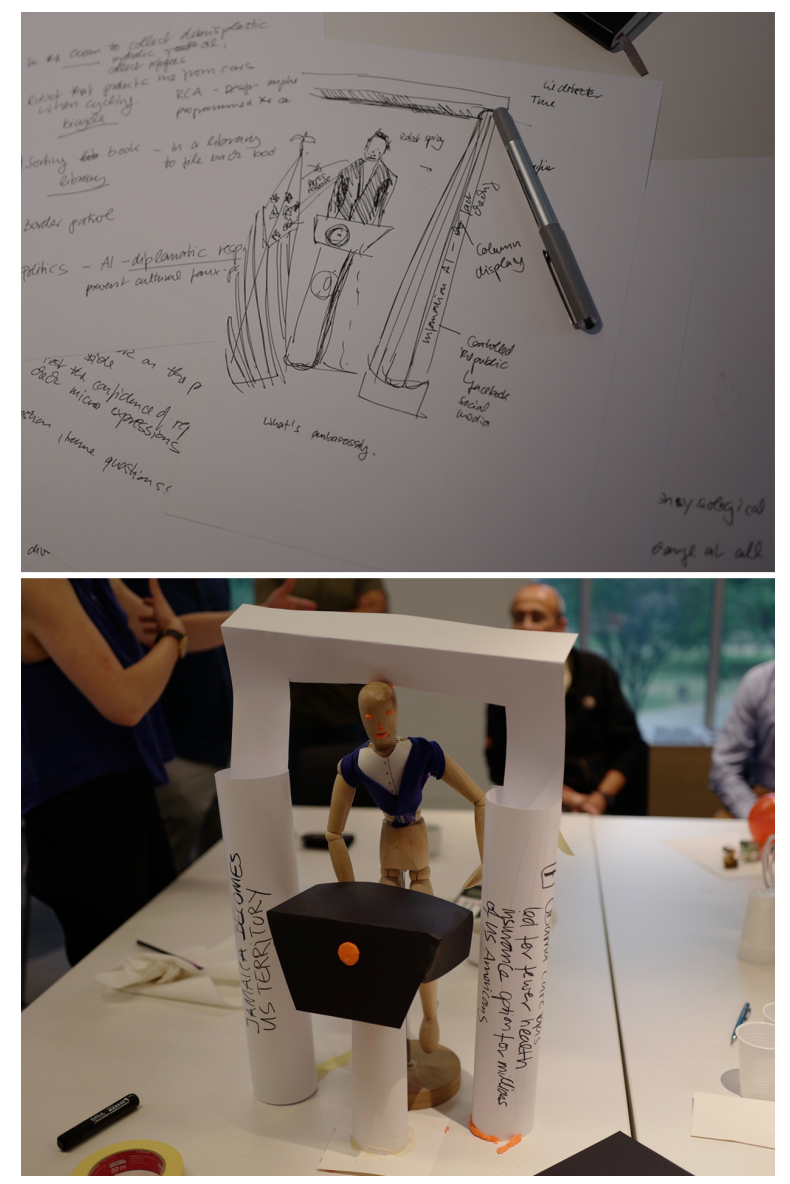

Figure 8: Design outcome of Group 2: (top) Sketch of the concept (bottom) A robot as a political avatar. Beside a lectern, two columns containing digital signage continuously display true or false news from each main political party.

From the design session of the workshop, each group produced different roles and scenarios for embarrassment and intelligent machines. The four groups' design scenario summaries are described below.

Group 1 designed a series of two robots to soothe humans' embarrassment during social interactions. The robots would constantly move around and as a result produce footsteps or vibration noises. The intention was to create conversations about them, similar to the way dog owners tend to congregate whilst walking their dogs in parks (See Figure 7).

Group 2 produced a robot that acts as a representative avatar to show human embarrassment. The robot would play the role of a press secretary to a president during situations of public exposure (e.g., press conference) in order to control the spread of fake news. The robot should maintain a neutral political position from either right or left wing, however it would express emotion through sweating if a specific question would cause one particular party to be embarrassed (See Figure 8).

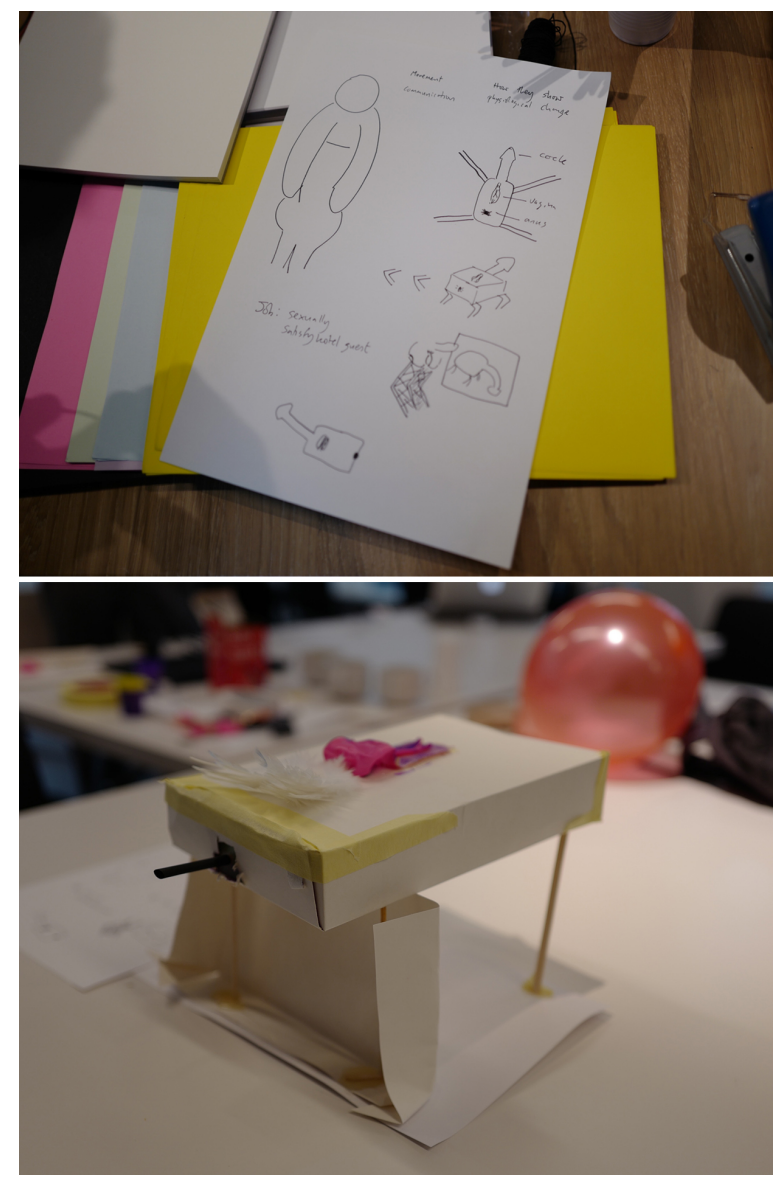

Figure 9: Design outcome of Group 3: (top) Sketch of the concept (bottom) A sex robot that plays a role to generate human's humiliation. The robot features both sexual organs of female and male and four legs. The robot can independently move around. It bows its head, "like a dog", as the signal of embarrassment.

Group 3 presented a robot that exists to fulfill a desire to be embarrassed. The robot, a sex machine, would work for any couple who are interested in having a third party in their sex life or using 'humiliation' to stimulate their desires. The robot expresses embarrassment by changing its head position (i.e., lowing down as if it is bowing). (See Figure 9).

The designed robot of Group 4 was an intelligent machine that is expresses empathic embarrassment for an embarrassed human. The robot is an ATM, which makes a sound when an individual has just realized their account has not enough money. The machine would melt the bank card removing the need for the individual to get it back (See Figure 10).

The way embarrassment was envisioned as being realized varied quite widely. Group 1 said the robots are constantly moving, vibrating, making noises, or producing foot-prints once the owner has entered a social situation with any other. Group 2 indicated that the robot does not need to be able to recognize human expressions 


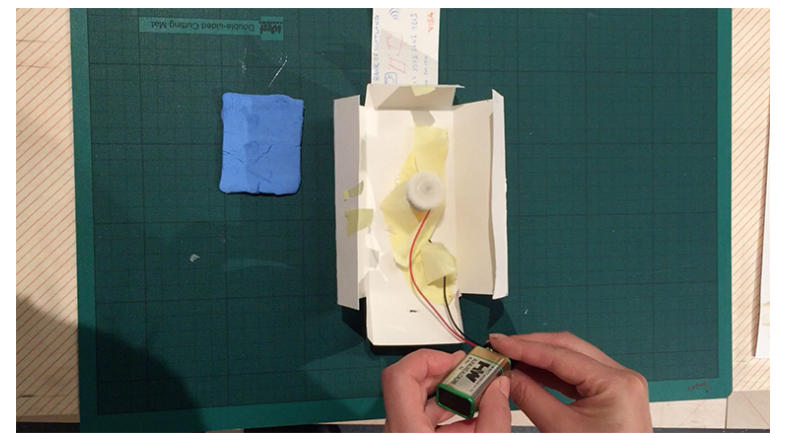

Figure 10: Design outcome of Group 4: An ATM robot which expresses empathetic embarrassment for human. The robot opens the ATM cover and makes a noise as the embarrassed reaction.

because it is simply an avatar of its owner. Group 3 explained how their robot realizes it failed to humiliate the person who requested to be, by rotating the body parts which creates noise. As the Group 4's robot is installed inside of an existing machine, it a recognition of the user of the machine's expression, also it reads the situation by the given data from the machine.

Two groups used noise making and movement as the process of manifestation (i.e., signals of embarrassment). Sweat generation, heat production and graphic production were stated as a sign by other groups.

\section{DISCUSSION}

Together with the returned probes, the workshop's design outcomes and the round-table discussion produced a variety of playful, critical perspectives on the concept of embarrassed robots. In the following section, we summarize some themes that are illustrated by these outcomes and discuss the potential implications for creating an intelligent machine that can express embarrassment. To generate these themes, we created a layered data-set which includes participants' interpretations of cultural probes, participants' insights during the workshop (e.g., the outcome presentations, the round-table discussion), design of artifacts they produced (e.g., the illustration, the material choices), direct observations, email communications and pictures of workshop documentation. The 'thick' descriptions created in this way provide the background to the qualitative summary that follows.

\subsection{The Role of Embarrassed Robots}

The first theme emerging from the outcomes was the challenge that the concept of embarrassed robots posed for participants assumptions about how robots could or should function. In some cases this was an explicit denial of the relevance of embarrassment or emotion for robots. The majority of participants stated their previous understanding of robots' role in our society was a machine that performs a work task as a job. Some participants mentioned a negative perception towards robots has formed due to the notion of robots as a substitute or replacement for humans. Participants reported that the design process and questions helped to broaden their perspective on the possible role of the robots and the potential value of using embarrassment to deal with mistakes and to facilitate an emotional connection with humans. To a large extent this reflects the stated agenda of the cultural probes and workshop. More interesting are the diversity of scenarios and uses of embarrassment generated through this process. The alternative roles of robots through the design outcomes are discussed below:

Mitigation: Group 1 illustrated the role of the robot as a medium to 'remove or reduce awkwardness' in a social interaction environment. The design takes an alternative approach for applying the role of embarrassment from the workshop brief: instead of making an 'embarrassed robot', the idea suggests a robot that could mitigate an individual's (i.e., the owner or operator of the robot) embarrassment by creating diversions or failing tasks. The approach offers a perspective on robots as a helpful third-party participant or mediator to fill or to connect a social-gap between individuals in our everyday social interactions. The outcome highlights one of the critical roles of embarrassment in Goffman's argument about the impression management process, which creates intimacy among people.

Mediation: Group 2 proposed a robot as a 'Social Avatar' of an individual who controls the robot (i.e., the owner). The role of the avatar is to prevent the formulation of fake news by removing the ability of a third party to misread the social behaviors of its owner. The Social Avatar as a concept has gathered attention from not only the study of VR/AR but also the social media industry. For example, Facebook [28] has shown interest in using the concept of the Social Avatar for improving their communication platform. In this design scenario, embarrassment is used as a way of exposing what Goffman would characterize as a conflict between the virtual (projected) self and the (behavioral) real self but effectively reverses their roles for impression management. The design also highlights one of distinctive characteristics of embarrassment among social emotions- once it is experienced its signals are to some extent involuntary (i.e., it is expressed through either behavioral or physiological changes). The idea raises a number of interesting questions: Why would a robot function to expose the truth of the individual who is 'hiding behind' the robot to other people? This design tunes into the intuition that embarrassment is somehow a more authentic display of a person's character than more discretionary emotional displays such as smiles and laughter since it represents a failure of impression management. However, this also raises the practical question of why someone would choose to expose these moments more than necessary.

Facilitation: Group 3 proposed the robot's role as a machine that could provoke the experience of social emotions through the intention to be embarrassed or humiliated as a form of emotional or sexual satisfaction. The idea that the robot should exacerbate embarrassment, like the previous example, highlights participants perception of the potential for embarrassment to directly enhance interaction. The concept asks how embarrassment could be used in such an extreme and extended form by transforming it into a stronger form: humiliation. This questions Goffman's precept that people work to avoid embarrassment and underlines the limitations of a naïve concept of emotions such as embarrassment as 'good' or 'bad' independently of the diversity of forms of human social encounter. Emotional displays of all kinds can always be co-opted as 
resources for staging particular kinds of interaction; a robot assisted production of the mise en scène. This opens up some interesting possibilities: In what other situations would we want a machine to help us perform a social emotion? What kind of signals could the robot display as embarrassment, as a way of showing its failure to deliver a task? What other emotional engagements could be facilitated by a robot?

Displaying Empathy: Group 4 focused on embarrassment as a core cause of empathetic identification in social experience, and applied that to the robot design scenario. By showing the empathetic reaction to the embarrassed individuals, the robot could build a sense of "we-ness" (i.e., "sense of the state of the bond")[80], with the individuals. Lofland [59] described Goffman [35]'s view on experiencing social emotions in social interaction as a process for individuals to recognize the existence of others who share the empathetic understanding of what they have felt. An example that shows the vital impact of recognizing the state of the bond in social interaction can be found from a study by Carrère et al. [10], which discusses the critical relationship between the level of sensing "we-ness" and material stability in newlywed couples. The concept offered a critical thought about the role of the Embarrassed Robot as a 'consolidator' who could share in our everyday social interactions through involvement with social emotions, which Lofland referred as "[...] the most fundamental and painful social experiences".

\subsection{The Form and Signal of 'Human-like' Robots}

A variety of approaches to the forms and signals that could communicate a machine's embarrassment were observed. For the appearance of the robot, most of the workshop participants designed a form of non-human object (e.g., box shape or organic form) or applied their thinking to an existing machine, while one group used a human-like physicality. Among the non-human object robots, only one workshop outcome used representations of human body parts and movements in their design. Although most of returned probes featured human-like characteristics, none of them suggested a humanoid shaped robot. The limited use of humanoid shapes in the design explorations shows that the robot's 'human-likeness' is not dependent on the physical design mimicking the human form.

People tend to illustrate the signals of embarrassment through changes in either movement, facial features, color or noise. This result indicates that the physical or behavioral change between the non-embarrassed and embarrassed state is key to the robot's signaling of embarrassment. This points to the importance of the dynamics of robots embarrassment displays. This is because, embarrassment has distinct expressive characteristics among social emotions: with particular movements and posture changes that signal the temporary displacement of the primary activity.

We also attempted to identify which forms and signals might contribute towards human-like aesthetics of objects without employing an actual human body, or body parts. We found a common theme that was mentioned throughout the outcomes, which would allow participants to perceive an object as 'alive': at least one human characteristic feature or function. However these could be minimal.
Some workshop participants mentioned that two dots on an object could be seen as human eyes, which creates the perception that the object is similar to a human. Across most of the returned probes there was a second common theme - instead of applying multiple human-like physical features, people tended to use one or two, only. The majority of the workshop participants also spoke about voice (i.e., speaking or narrative function) from a machine (e.g., navigator, robots from fictional films) could deliver 'human-likeness' without presenting a physical body.

The discussion about the 'humanlike' signals of the robots did not reach a single conclusion but highlighted a theme of 'mobility' as a behavior or function of the machine which was seen within most of design outcomes.

\subsection{Discovering A New Role for Embarrassment}

Arguably robots, like people, will always encounter social situations that are too complex or too unfamiliar for them to deal with perfectly. If we abandon the fantasy of prefect competence we create new opportunities for the design of human-robot interactions. This proposal is analogous to Chalmers' concept of "seamful design" which recognizes that technologies always fail to some extent but that these failures create opportunities for design [11]. Here the 'seams' of interest are the opportunities created by temporary breakdowns in social interaction. Embarrassment plays a fundamental role in these breakdowns but it has not so far been exploited in affective robotics.

The outcomes reported here demonstrate the potential of embarrassment not only as a recognition of 'error' and strategy for mitigation and graceful failure but also as an important resource for building trust and empathy in HRI, one that can be used to mediate and facilitate new kinds of interaction. They demonstrate the pervasive relevance of embarrassment in interaction and the diversity of social situations in which it could play a role as a way of recognizing the impact of social norms. The ATM machine, mentioned earlier as an outcome of the workshop, suggests how another party's signals of embarrassment effectively communicates a kind of solidarity with the embarrassed individual. Although vicarious embarrassment has been discussed in the fields of psychology and neuroscience (e.g., [53, 54]), the positive emotional engagement between the embarrassed individual and others who express vicarious embarrassment have not been recognized in design or robotics literatures. Robots with the capacity to recognize and respond to embarrassment signals from others can exploit this to help build acceptance and promote stronger human-robot relationships. People typically bond more quickly and more strongly with others who show empathy [75].

More fundamentally, Cooley [14]'s concept of the Looking-Glass Self proposes that the process of formulating a self-concept depends primarily on the reaction of others. This informs Goffman's argument about the importance of embarrassment as an essential part of the foundations of social interaction. We speculate that embarrassment will prove to be pivotal for the development of truly social robots. Moments of embarrassment expose the assumed basis of intersubjectivity and uncover the social norms operating in a particular relationship, community or culture. This provides robotic 
systems with opportunities not just to mitigate errors but to build increasingly sophisticated models of the social world and update their models of their own social identities.

\section{LIMITATION AND FUTURE WORK}

Although speculative design provides useful ways to explore novel concepts and provoke debate it does not systematically generalize and does not generate design principles. This discussion also raises many technical and practical questions not least of which are how we could actually engineer a system that can recognize, produce and learn from signals of embarrassment.

The return rate of the cultural probes was low (see also [37]). Despite over 300 copies of each patterns being given away, we only received 9 images through the channels we had specified for return (i.e., email and Instagram). Thirteen images were collected in the drop-in making sessions. The situational environments were also often neglected in the images. Although the drop-in session helped to increase the number of returns, the participants tended to take a photo of the prototype without considering the background context within which it is supposed to be placed in order to deliver the cause of embarrassment. The workshop also had a relatively low attendance. The registration was free but there was a limit on venue capacity, people who registered did not cancel their place in advance, which potentially contributed to the lower attendance result. With more participants, we would expect a greater variety of ideas and more insightful findings through the different backgrounds and knowledge they would bring to the workshop.

Our findings suggest the potential of employing embarrassment as a constructive social emotion for affective robotics. Through the findings we have identified the possible roles, forms and signals of the Embarrassed Robots. Based on the outcomes, we aim to further explore the possible physical design of the Embarrassed Robots and better illustrate future scenarios on how life might look if domestication of the robots becomes mainstream.

\section{CONCLUSION}

Social interaction is one of the most complex challenges for robotics and robots will inevitably sometimes fail to meet these challenges. Signals of embarrassment can help robots to cope with these situations and to enlist help. However, embarrassment has not yet played a significant role in engineering human-robot interactions. Speculative design provides a way to address some key questions about the future potential of embarrassment for HRI: What roles could embarrassed robots play in our daily lives? What forms and signals of robot embarrassment could communicate the emotion? And what form and signal of a robot could be perceived as close to a 'human-like' machine? This work opens a diverse set of possibilities as to why such a robot would be useful in our social interactions for removing awkwardness, replacing the human as a form of embarrassment defense, providing empathetic connections and also generating embarrassment as a desired emotion. One point which is common to all the design ideas is that an Embarrassed Robot would create a better impression and therefore help to successfully integrate robotics into human life. Social, political and ethical implications are also highlighted (e.g., fake news, sex robots, the possibility and legitimacy of empathetic reactions from a machine, etc). The simplest forms and signals of robot embarrassment exploit characteristics of human displays of human embarrassment. However, a robot's appearance does not need to adopt a humanoid form. People can perceive a robot as human-like even on the basis of a single characteristic: the characteristics do not need to be a physical appearance - for example the ability to speak would be sufficient. From the analysis of our studies, we argue that the answer to the question in the title of this paper is Robots Should Blush.

\section{ACKNOWLEDGMENTS}

We are grateful to all speakers and participants of our studies for their time and participation. We deeply thank Unit Lab for their help co-organzing the design workshop. We also thank Owen Wells, Hyung-ok Park, Koby Barhad and Dr. Ildar Farkhatdinov for their advice to improve the project. This work was funded and supported by EPSRC and AHRC Centre for Doctoral Training in Media and Arts Technology (grant number: EP/L01632X/1) of Queen Mary, University of London and Designers in Residence program of the Design Museum, London.

\section{REFERENCES}

[1] Julian M Angel-Fernandez and Andrea Bonarini. 2016. Robots Showing Emotions: Emotion Representation with no bio-inspired body. Interaction Studies 17, 3 (2016), 408-437.

[2] Jens Asendorpf. 1990. The expression of shyness and embarrassment. In Shyness and embarrassment: Perspectives from social psychology (1 ed.), W. Ray Crozier (Ed.). Cambridge University Press, Cambridge, 87-118.

[3] James Auger. 2013. Speculative design: crafting the speculation. Digital Creativity 24, 1 (2013), 11-35. https://doi.org/10.1080/14626268.2013.767276

[4] James Auger and Jimmy Loizeau. 2010. Happylife. http://www.auger-loizeau. com/projects/happylife Last accessed on 11th Sep 2020.

[5] Christoph Bartneck, Timo Bleeker, Jeroen Bun, Pepijn Fens, and Lynyrd Riet. 2010. The influence of robot anthropomorphism on the feelings of embarrassment when interacting with robots. Paladyn 1, 2 (2010), 109-115. https://doi.org/10. 2478/s13230-010-0011-3

[6] Ben Bedwell and Theresa Caruana. 2012. Encouraging Spectacle to Create SelfSustaining Interactions at Public Displays. In Proceedings of the 2012 International Symposium on Pervasive Displays (Porto, Portugal) (PerDis '12). Association for Computing Machinery, New York, NY, USA, Article 15, 6 pages. https://doi.org/ 10.1145/2307798.2307813

[7] Momotaz Begum, Richard W. Serna, David Kontak, Jordan Allspaw, James Kuczynski, Holly A. Yanco, and Jacob Suarez. 2015. Measuring the Efficacy of Robots in Autism Therapy: How Informative Are Standard HRI Metrics'. In Proceedings of the Tenth Annual ACM/IEEE International Conference on Human-Robot Interaction (Portland, Oregon, USA) (HRI '15). Association for Computing Machinery, New York, NY, USA, 335-342. https://doi.org/10.1145/2696454.2696480

[8] Julian Bleecker. 2009. Design Fiction: A Short Essay on Design, Science, Fact and Fiction. Near Future Laboratory. http://www.nearfuturelaboratory.com/2009/03/ 17/design-fiction-a-short-essay-on-design-science-fact-and-fiction

[9] Cynthia Breazeal. 2002. Designing Sociable Robots. MIT Press, Cambridge, MA, USA.

[10] Sybil Carrère, Kim T Buehlman, John M Gottman, James A Coan, and Lionel Ruckstuhl. 2000. Predicting marital stability and divorce in newlywed couples. , 42-58 pages. https://doi.org/10.1037/0893-3200.14.1.42

[11] Matthew Chalmers and Ian Maccoll. 2003. Seamful and seamless design in ubiquitous computing. Technical Report. In Proceedings of Workshop At the Crossroads: The Interaction of HCI and Systems Issues in UbiComp. 2003.

[12] Jung Ju Choi, Yunkyung Kim, and Sonya S. Kwak. 2014. Are You Embarrassed? The Impact of Robot Types on Emotional Engagement with a Robot. In Proceedings of the 2014 ACM/IEEE International Conference on Human-Robot Interaction (Bielefeld, Germany) (HRI '14). Association for Computing Machinery, New York, NY, USA, 138-139. https://doi.org/10.1145/2559636.2559798

[13] Mina Choi, Rachel Kornfield, Leila Takayama, and Bilge Mutlu. 2017. Movement Matters. In Proceedings of the 2017 CHI Conference on Human Factors in Computing Systems. ACM, New York, NY, USA, 325-335. https://doi.org/10.1145/3025453. 3025734

[14] Charles Cooley. [1902] 1922. The Social Self - 1. The Meaning of "I". In Human Nature and the Social Order (1 ed.). Charles Scribner's Sons, New York, 168-210.

[15] Torbjørn Dahl and Maged Boulos. 2013. Robots in Health and Social Care: A Complementary Technology to Home Care and Telehealthcare? Robotics 3, 1 (2013), 1-21. https://doi.org/10.3390/robotics3010001 
[16] Kerstin Dautenhahn, Chrystopher L. Nehaniv, Michael L. Walters, Ben Robins, Hatice Kose-Bagci, and Mike Blow. 2009. KASPAR - a Minimally Expressive Humanoid Robot for Human-Robot Interaction Research. Appl. Bionics Biomechanics 6, 3,4 (July 2009), 369-397. https://doi.org/10.1080/11762320903123567

[17] Pegah Soleimman Dehkordi, Hadi Moradi, Maryam Mahmoudi, and Hamid Reza Pouretemad. 2015. The Design, Development, and Deployment of RoboParrot for Screening Autistic Children. International fournal of Social Robotics 7, 4 (01 Aug 2015), 513-522. https://doi.org/10.1007/s12369-015-0309-8

[18] Sebastian Deterding. 2018. Alibis for Adult Play: A Goffmanian Account of Escaping Embarrassment in Adult Play. Games and Culture 13, 3 (2018), 260-279. https://doi.org/10.1177/1555412017721086

[19] Sebastian Deterding, Andrés Lucero, Jussi Holopainen, Chulhong Min, Adrian Cheok, Annika Waern, and Steffen Walz. 2015. Embarrassing Interactions. In Proceedings of the 33rd Annual ACM Conference Extended Abstracts on Human Factors in Computing Systems (Seoul, Republic of Korea) (CHI EA '15). Association for Computing Machinery, New York, NY, USA, 2365-2368. https://doi.org/10. 1145/2702613.2702647

[20] Christian Dindler and Ole Sejer Iversen. 2007. Fictional Inquiry-design collaboration in a shared narrative space. CoDesign 3, 4 (12 2007), 213-234. https://doi.org/10.1080/15710880701500187

[21] Anthony Dunne and Fiona Raby. 2007. TECHNOLOGICAL DREAMS SERIES NO.1, ROBOTS. http://dunneandraby.co.uk/content/projects/10/0\# Last accessed on 12th Sep 2020

[22] Anthony Dunne and Fiona Raby. 2013. Speculative Everything: Design, Fiction, and Social Dreaming. MIT Press, Cambridge.

[23] Robert J Edelmann. 1981. Embarrassment: The state of research. Current Psychological Reviews 1, 2 (1981), 125-137. https://doi.org/10.1007/BF02979260

[24] Robert J Edelmann. 1987. The psychology of embarrassment. Wiley, Chichester.

[25] Robert J. Edelmann and Sarah E. Hampson. 1979. Changes in non-verbal behaviour during embarrassment. British fournal of Social and Clinical Psychology 18, 4 (1979), 385-390. https://doi.org/10.1111/j.2044-8260.1979.tb00908.x

[26] R. J. Edelmann and S. E. Hampson. 1981. The Recognition of Embarrassment Personality and Social Psychology Bulletin 7, 1 (1981), 109-116. https://doi.org/10. 1177/014616728171017

[27] S. Embgen, M. Luber, C. Becker-Asano, M. Ragni, V. Evers, and K. O. Arras 2012. Robot-specific social cues in emotional body language. In 2012 IEEE ROMAN: The 21st IEEE International Symposium on Robot and Human Interactive Communication. IEEE, Paris, France, 1019-1025. https://doi.org/10.1109/ROMAN 2012.6343883

[28] Facebook. 2016. Keynote D2 - Videos - Facebook for Developers. https:// developers.facebook.com/videos/f8-2016/keynote-d2/ Last accessed on 11th Aug 2017.

[29] Francesco Ferrari, Maria Paola Paladino, and Jolanda Jetten. 2016. Blurring Human-Machine Distinctions: Anthropomorphic Appearance in Social Robots as a Threat to Human Distinctiveness. International fournal of Social Robotics 8 , 2 (01 Apr 2016), 287-302. https://doi.org/10.1007/s12369-016-0338-y

[30] Terrence Fong, Illah Nourbakhsh, and Kerstin Dautenhahn. 2003. A survey of socially interactive robots. Robotics and Autonomous Systems 42, 3-4 (2003), 143166. https://doi.org/10.1016/S0921-8890(02)00372-X arXiv:arXiv:1011.1669v3

[31] Bill Gaver, Tony Dunne, and Elena Pacenti. 1999. Design: Cultural Probes. Interactions 6, 1 (Jan. 1999), 21-29. https://doi.org/10.1145/291224.291235

[32] William W. Gaver, Andrew Boucher, Sarah Pennington, and Brendan Walker 2004. Cultural Probes and the Value of Uncertainty. Interactions 11, 5 (Sept. 2004), 53-56. https://doi.org/10.1145/1015530.1015555

[33] Erving Goffman. 1956. Embarassment and social organization. The American fournal of Sociology 62, 3 (1956), 264-271.

[34] Erving Goffman. 1959. The Presentation of Self in Everyday Life. Anchor Books, New York.

[35] Erving Goffman. 1963. Stigma. Prentice-Hall, Englewood Cliffs, N.J.

[36] Erving Goffman. 1967. Interaction Ritual: Essays on Face-to-Face Behavior (1 ed.) Doubleday, Garden City, NY.

[37] Connor Graham, Mark Rouncefield, Martin Gibbs, Frank Vetere, and Keith Cheverst. 2007. How Probes Work. In Proceedings of the 19th Australasian Conference on Computer-Human Interaction: Entertaining User Interfaces (Adelaide, Australia) (OZCHI '07). Association for Computing Machinery, New York, NY, USA, 29-37. https://doi.org/10.1145/1324892.1324899

[38] Joan M. Greenbaum and M. Kyng (Eds.). 1991. Design at Work: Cooperative Design of Computer Systems. L. Erlbaum Associates Inc., Hillsdale, NJ, USA.

[39] Edward Gross and Gregory P. Stone. 1964. Embarrassment and the Analysis of Role Requirements. Amer. F. Sociology 70, 1 (1964), 1-15. https://doi.org/10.1086/ 223733

[40] B. S. Han, A. Hong Yee Wong, Y. K. Tan, and H. Li. 2010. Using design methodology to enhance interaction for a robotic receptionist. In 19th International Symposium in Robot and Human Interactive Communication. IEEE, Viareggio, Italy, 797-802.

[41] David Hanson. 2011. Why We Should Build Humanlike Robots. IEEE Spectrum: Technology, Engineering, and Science News. https://spectrum.ieee.org/ automaton/robotics/humanoids/why-we-should-build-humanlike-robots Last accessed on 12 th Jul 2018
[42] David Hanson, Andrew Olney, Ismar a Pereira, and Marge Zielke. 2005. Upending the Uncanny Valley. Proceedings of the national conference on artificial intelligence 20, 4 (2005), 24-31.

[43] Christine R Harris. 2001. Cardiovascular responses of embarrassment and effects of emotional suppression in a social setting. Journal of Personality and Social Psychology 81, 5 (2001), 886-897. https://doi.org/10.1037/0022-3514.81.5.886

[44] Cory J Hayes, Maryam Moosaei, and Laurel D Riek. 2016. Exploring implicit human responses to robot mistakes in a learning from demonstration task. In 2016 25th IEEE International Symposium on Robot and Human Interactive Communication (RO-MAN). IEEE, IEEE, New York, NY, USA, 246-252. https://doi.org/10.1109/ROMAN.2016.7745138

[45] Patrick G. T. Healey. 2021. Human-Like Communication. In Human-Like Machine Intelligence, Stephen Muggleton and Nick Chater (Eds.). Oxford University Press, Oxford, England.

[46] Christian Heath. 1988. Embarrassment and interactional organization. In Erving Goffman: Exploring the Interaction Order, Paul Drew and Anthony Wootton (Eds.). Polity Press, Cambridge, 136-160.

[47] Deanna Hood, Séverin Lemaignan, and Pierre Dillenbourg. 2015. When Children Teach a Robot to Write. In Proceedings of the Tenth Annual ACM/IEEE International Conference on Human-Robot Interaction. ACM, Portland, OR, USA, 83-90. https: //doi.org/10.1145/2696454.2696479

[48] Amy Huggard, Anushka De Mel, Jayden Garner, Cagdas Toprak, Alan Chatham, and Florian Mueller. 2013. Musical Embrace: Facilitating Engaging Play Experiences through Social Awkwardness. Conference on Human Factors in Computing Systems - Proceedings 2013-April (2013), 3067-3070. https://doi.org/10.1145/ 2468356.2479612

[49] Hiroshi Ishiguro. 2006. Interactive Humanoids and Androids As Ideal Interfaces for Humans. In Proceedings of the 11th International Conference on Intelligent User Interfaces. ACM, New York, NY, USA, 2-9. https://doi.org/10.1145/1111449. 1111451

[50] Malte F. Jung. 2017. Affective Grounding in Human-Robot Interaction. In Proceedings of the 2017 ACM/IEEE International Conference on Human-Robot Interaction (Vienna, Austria) (HRI '17). Association for Computing Machinery, New York, NY, USA, 263-273. https://doi.org/10.1145/2909824.3020224

[51] Dacher Keltner. 1995. Signs of appeasement: Evidence for the Distinct Displays of Embarrassment, Amusement, and Shame. Journal of Personality and Social Psychology 68, 3 (1995), 441-454. https://doi.org/10.1037/0022-3514.68.3.441

[52] Dacher Keltner and Branda N. Buswell. 1996. Evidence for the Distinctness of Embarrassment, Shame, and Guilt: A Study of Recalled Antecedents and Facial Expressions of Emotion. Cognition \& Emotion 10, 2 (1996), 155-172. https: //doi.org/10.1080/026999396380312

[53] Dacher Keltner and Brenda N. Buswell. 1997. Embarrassment: Its distinct form and appeasement functions. Psychological Bulletin 122, 3 (1997), 250-270. https: //doi.org/10.1037/0033-2909.122.3.250

[54] Sören Krach, Jan Christopher Cohrs, Nicole Cruz de Echeverría Loebell, Tilo Kircher, Jens Sommer, Andreas Jansen, and Frieder Michel Paulus. 2011. Your Flaws Are My Pain: Linking Empathy To Vicarious Embarrassment. PLOS ONE 6, 4 (04 2011), 1-9. https://doi.org/10.1371/journal.pone.0018675

[55] Min Kyung Lee, Jodi Forlizzi, Paul E. Rybski, Frederick Crabbe, Wayne Chung, Josh Finkle, Eric Glaser, and Sara Kiesler. 2009. The Snackbot: Documenting the Design of a Robot for Long-term Human-robot Interaction. In Proceedings of the 4th ACM/IEEE International Conference on Human Robot Interaction. ACM, New York, NY, USA, 7-14. https://doi.org/10.1145/1514095.1514100

[56] Angelica Lim and Hiroshi G. Okuno. 2014. The MEI robot: Towards using motherese to develop multimodal emotional intelligence. IEEE Transactions on Cognitive and Developmental Systems 6, 2 (2014), 126-138. https://doi.org/10. 1109/TAMD.2014.2317513

[57] Joseph Lindley and Paul Coulton. 2015. Back to the Future: 10 Years of Design Fiction. In Proceedings of the 2015 British HCI Conference (Lincoln, Lincolnshire, United Kingdom) (British HCI '15). ACM, New York, NY, USA, 210-211. https: //doi.org/10.1145/2783446.2783592

[58] Joseph Lindley and Paul Coulton. 2016. Pushing the Limits of Design Fiction: The Case For Fictional Research Papers. In Proceedings of the 2016 CHI Conference on Human Factors in Computing Systems (San Jose, California, USA) (CHI '16). Association for Computing Machinery, New York, NY, USA, 4032-4043. https: //doi.org/10.1145/2858036.2858446

[59] John Lofland. 1980. Early Goffman: Style, Structure, Substance, Soul. In The View from Goffman, Jason Ditton (Ed.). Palgrave Macmillan UK, London, 24-51. https://doi.org/10.1007/978-1-349-16268-0_2

[60] Thomas Markussen and Eva Knutz. 2013. The Poetics of Design Fiction. In Proceedings of the 6th International Conference on Designing Pleasurable Products and Interfaces (Newcastle upon Tyne, United Kingdom) (DPPI '13). ACM, New York, NY, USA, 231-240. https://doi.org/10.1145/2513506.2513531

[61] Nobuyoshi Matsumoto, Hiroyuki Fujii, and Michio Okada. 2006. Minimal design for human-agent communication. Artificial Life and Robotics 10, 1 (01 Jul 2006), 49-54. https://doi.org/10.1007/s10015-005-0377-1

[62] Derek McColl, Alexander Hong, Naoaki Hatakeyama, Goldie Nejat, and Beno Benhabib. 2016. A Survey of Autonomous Human Affect Detection Methods for 
Social Robots Engaged in Natural HRI. Journal of Intelligent \& Robotic Systems 82, 1 (2016), 101-133. https://doi.org/10.1007/s10846-015-0259-2

[63] Matthias R Mehl, Simine Vazire, Nairán Ramírez-Esparza, Richard B Slatcher, and James W Pennebaker. 2007. Are women really more talkative than men? Science 317, 5834 (2007), 82-82. https://doi.org/10.1126/science.1139940

[64] Sandra Metts and William R. Cupach. 1989. Situational influence on the use of remedial strategies in embarrassing predicaments. Communication Monographs 56, 2 (06 1989), 151-162. https://doi.org/10.1080/03637758909390256

[65] Rowland S. Miller. 1987. Empathic embarrassment: Situational and personal determinants of reactions to the embarrassment of another. Fournal of Personality and Social Psychology 53, 6 (1987), 1061-1069. https://doi.org/10.1037/00223514.53.6.1061

[66] Rowland S. Miller. 1992. The Nature and Severity of Self-Reported Embarrassing Circumstances. Personality and Social Psychology Bulletin 18, 2 (1992), 190-198. https://doi.org/10.1177/0146167292182010

[67] Nicole Mirnig, Gerald Stollnberger, Markus Miksch, Susanne Stadler, Manuel Giuliani, and Manfred Tscheligi. 2017. To err is robot: How humans assess and act toward an erroneous social robot. Frontiers in Robotics and AI 4 (2017), 21.

[68] Andre Modigliani. 1971. Embarrassment, facework, and eye contact: Testing a theory of embarrassment. Fournal of Personality and Social Psychology 17, 1 (1971), 15-24. https://doi.org/10.1037/h0030460

[69] Masahiro Mori, Karl F. MacDorman, and Norri Kageki. 2012. The uncanny valley. IEEE Robotics and Automation Magazine 19, 2 (2012), 98-100. https: //doi.org/10.1109/MRA.2012.2192811

[70] Yoshinori Nakagawa, Kaechang Park, Hirotada Ueda, and Hiroshi Ono. 2014 Driving Assistance with Conversation Robot for Elderly Drivers. In Universal Access in Human-Computer Interaction. Aging and Assistive Environments, Constantine Stephanidis and Margherita Antona (Eds.). Springer International Publishing, Cham, 750-761.

[71] International Federation of Robotics. 2019. executive summary world robotics 2019 (1 ed.). other. International Federation of Robotics. https://ifr.org/downloads/ press2018/Executive\%20Summary\%20WR\%202019\%20Industrial\%20Robots.pdf

[72] Rikke Ørngreen and Karin Levinsen. 2017. Workshops as a research methodology. Electronic Journal of e-Learning 15, 1 (2017), 70-81.

[73] Xueni Pan and Antonia F. de C. Hamilton. 2015. Automatic imitation in a rich social context with virtual characters. Frontiers in Psychology 6, June (2015), 1-10. https://doi.org/10.3389/fpsyg.2015.00790

[74] Chiara Piezzo and Kenji Suzuki. 2017. Feasibility study of a socially assistive humanoid robot for Guiding elderly individuals during walking. Future Internet 9, 3 (2017), 30. https://doi.org/10.3390/fi9030030

[75] Helen Riess. 2017. The Science of Empathy. Fournal of patient experience 4, 2 (06 2017), 74-77. https://doi.org/10.1177/2374373517699267

[76] B. Robins, F. Amirabdollahian, Z. Ji, and K. Dautenhahn. 2010. Tactile interaction with a humanoid robot for children with autism: A case study analysis involving user requirements and results of an initial implementation. In 19th International Symposium in Robot and Human Interactive Communication. IEEE, Viareggio, Italy, 704-711. https://doi.org/10.1109/ROMAN.2010.5598641

[77] M. A. Salichs, R. Barber, A. M. Khamis, M. Malfaz, J. F. Gorostiza, R. Pacheco, R. Rivas, A. Corrales, E. Delgado, and D. Garcia. 2006. Maggie: A Robotic Platform for Human-Robot Social Interaction. In 2006 IEEE Conference on Robotics, Automation and Mechatronics. IEEE, Bangkok, Thailand, 1-7. https: //doi.org/10.1109/RAMECH.2006.252754
[78] Samsung. 2019. Meet the Samsung Bots: Your Companions of the Future. online. https://news.samsung.com/global/video-meet-the-samsung-bots-yourcompanions-of-the-future

[79] Shane Saunderson and Goldie Nejat. 2019. How Robots Influence Humans: A Survey of Nonverbal Communication in Social Human-Robot Interaction. International Journal of Social Robotics 11, 4 (2019), 575-608. https://doi.org/10. 1007/s12369-019-00523-0

[80] Thomas J. Scheff. 2003. Looking Glass Selves: the Cooley/Goffman Conjecture[1]

[81] Thomas J Scheff. 2005. Looking-Glass Self: Goffman as Symbolic Interactionist. Symbolic Interaction 28, 2 (2005), 147-166. https://doi.org/10.1525/si.2005.28.2.147

[82] Gün R. Semin and A. S. R. Manstead. 1982. The social implications of embarrassment displays and restitution behaviour. European fournal of Social Psychology 12, 4 (2021/01/09 1982), 367-377. https://doi.org/10.1002/ejsp.2420120404

[83] Don Shearn, Erik Bergman, Katherine Hill, Andy Abel, and Lael Hinds. 1990. Facial Coloration and Temperature Responses in Blushing. Psychophysiology 27, 6 (1990), 687-693. https://doi.org/10.1111/j.1469-8986.1990.tb03194.x

[84] Don Shearn, Erik Bergman, Katherine Hill, Andy Abel, and Lael Hinds. 1992. Blushing as a Function of Audience Size. Psychophysiology 29, 4 (1992), 431-436. https://doi.org/10.1111/j.1469-8986.1992.tb01716.x

[85] Softbank Robotics. 2014. Who is Pepper? https://www.softbankrobotics.com/ emea/en/robots/pepper. Last accessed on 15th Jul 2018.

[86] Fumihide Tanaka and Shizuko Matsuzoe. 2012. Children Teach a Care-Receiving Robot to Promote Their Learning: Field Experiments in a Classroom for Vocabulary Learning. Fournal of Human-Robot Interaction 1, 1 (2012), 78-95. https://doi.org/10.5898/JHRI.1.1.Tanaka

[87] June Price Tangney, Rowland S Miller, Laura Flicker, and Deborah Hill Barlow. 1996. Are shame, guilt, and embarrassment distinct emotions? , 1256-1269 pages. https://doi.org/10.1037/0022-3514.70.6.1256

[88] Diego Trujillo. 2011. With Robots. https://trujillodiego.com/work/withrobots. html Last accessed on 5th Sep 2020.

[89] Neil Usher. 2012. Pareidolic Robot. http://www.di12.rca.ac.uk/?projects= pareidolic-robot Last accessed on 12th Sep 2020

[90] Paulina Vélez, Katherine Gallegos, José Silva, Luis Tumalli, and Cristian Vaca. 2014. ROBSNA: Social Robot for Interaction and Learning Therapies. In Towards Autonomous Robotic Systems, Ashutosh Natraj, Stephen Cameron, Chris Melhuish, and Mark Witkowski (Eds.). Springer Berlin Heidelberg, Berlin, Heidelberg, 458469.

[91] Martin S Weinberg. 1968. Embarrassment: Its variable and invariable aspects. Social Forces 46, 3 (1968), 382-388. https://doi.org/10.2307/2574886

[92] Lesley A Withers and John C Sherblom. 2002. Embarrassment: The Communication of an Awkward Actor Anticipating a Negative Evaluation. Human Communication 11, 2 (2002), 237-254.

[93] Guang-Zhong Yang, Jim Bellingham, Pierre E. Dupont, Peer Fischer, Luciano Floridi, Robert Full, Neil Jacobstein, Vijay Kumar, Marcia McNutt, Robert Merrifield, Bradley J. Nelson, Brian Scassellati, Mariarosaria Taddeo, Russell Taylor, Manuela Veloso, Zhong Lin Wang, and Robert Wood. 2018. The grand challenges of Science Robotics. Science Robotics 3, 14 (2018), eaar7650. https: //doi.org/10.1126/scirobotics.aar7650

[94] Yaoxin Zhang, Wenxu Song, Zhenlin Tan, Huilin Zhu, Yuyin Wang, Cheuk Man Lam, Yifang Weng, Sio Pan Hoi, Haoyang Lu, Bella Siu Man Chan, Jiajia Chen, and Li Yi. 2019. Could social robots facilitate children with autism spectrum disorders in learning distrust and deception? Computers in Human Behavior 98 (2019), 140 - 149. https://doi.org/10.1016/j.chb.2019.04.008 